\title{
Study on Pricing and Service Strategy of We-media Platform Based on Two-sided Market Theory
}

\author{
Huakun Yan \\ Sino-US Global Logistics Institute, Antai College of Economics \& Management, Shanghai Jiaotong University, \\ Shanghai 20000, China; Fujian All-Trans Logistics CO.,LTD., Fuzhou 350000, China \\ Corresponding author. Email: yanhuakun8686@163.com
}

\begin{abstract}
This paper analyzes market characteristics and the advertising pricing and service investment strategies for we-media platforms. The results show that, the market size of the content providers and the cross-side externality influence the optimal price, which is difference in tradition media platform. The optimal price and service strategy depend on the price and demand elasticity of user, audience and advertiser. Designing differentiated content productions and improving service level based on the network externality effects are the key points for the platform operation.
\end{abstract}

Keywords: We-media platform; Two-sided market; Characteristic; Pricing strategy; Service strategy

\section{INTRODUCTION}

At present, the overall size of Chinese netizens has reached 1.011 billion, the Internet penetration rate has reached $71.6 \%$, the size of mobile phone netizens has reached 1.007 billion, and the proportion of netizens accessing the Internet through mobile phones has reached $99.6 \%$. The continuous development of the mobile internet and the innovation and improvement of the network infrastructure has provided an important prerequisite and guarantee for the development of the We Media industry. By the end of 2020, WeChat had over 1.2 billion monthly active users, Sina Weibo had 500 million monthly active users, and Headline had over 200 million monthly active users, making the We Media industry in China a considerable large market. In recent years, the development of China's We Media industry has become more and more rapid, and also gradually become the mainstream way of information dissemination, but its related theoretical research is relatively behind the industry practice.

The bilateral market theory is a framework theoretical guide to the development of the industry for We Media platforms and has a forward-looking reference value. Therefore, the key to the operation of the platform is how to make use of the characteristics of the bilateral market and the network scale effect of the platform to attract more We Media and audience users to join the platform. Based on clarifying the differences between
We Media platforms and traditional media platforms and combining bilateral market theory, this research analyses the market characteristics of We Media platforms, and then discusses the competition strategies of We Media platforms to provide countermeasure suggestions for the development of the We Media industry.

\section{COMPARATIVE ANALYSIS OF WE MEDIA PLATFORMS AND TRADITIONAL MEDIA PLATFORMS}

\subsection{We Media and We Media platforms}

The concept of We Media originated from Gillmor's discussion of News Media 3.0 in 2002: with the rise of the Internet, news media has undergone two significant transformations, firstly from News Media 1.0 (i.e. traditional media such as $\mathrm{TV}$, magazines and newspapers), to News Media 2.0 (i.e. new media such as mobile TV, digital magazines and online TV), then rapidly to News Media 3.0 (i.e. We Media), such as blogs, microblogs, WeChat, instant messaging, etc. In 2003 Bowman and Wills ${ }^{[1]}$ elaborated on the concept of We Media in their report: the audience of traditional media services, using the Internet and mobile communication technologies, to participate in the creation and dissemination of media messages. In the age of We Media, everyone is a creator and publisher of information, as well as a receiver of information. 
With the development of the We Media industry, some online video sites have added original video sharing sections to their original copyright purchasing model and content self-production model to provide users with channels to publish original video works, such as Youku and Tik Tok, which provide mobile users with channels to film, upload and share original content. In recent years, the expression of We Media has shifted from the simple form of text to the diversified development pattern of pictures, videos and audio, and there are also We Media platforms based on User Generated Content (UGC), i.e. user-produced content. Such platforms do not produce content themselves but provide content publishing, display and communication services for We Media and audience users. For example, We Media platforms such as Bai Jiahao, Headline and $\mathrm{Da} \mathrm{Yu}$ Hao are mainly in the form of graphics; We Media platforms such as Tik Tok, Kuai and Wesee are mainly in the form of video; We Media platforms such as Himalaya, Douban Musician and Dragonfly FM are mainly in the form of audio.

\subsection{Comparative analysis of We Media platforms and traditional media platforms}

The emergence of We Media platforms has not only changed the value chain of traditional media, but has also brought significant changes to the industry. The content providers and the audience, who were at the two ends of the traditional media industry chain, have become a direct interface between each other, with you having me and me having you, and diversified supply and diversified demand being directly matched, exchanged and interacted between the communicators and the audience, and between the producers and the consumers. The content production model of the We Media platform is based on user production, and there are three main types of serving clients in this model: the We Media side (content providers), the audience side (content consumers) and advertisers. The platform itself does not participate in the production or investment of content, nor does it purchase the copyright from content providers. Instead, it attracts and gathers both We Media and audience users to join the platform, providing services such as technical support and publicity channels for We Media, and broadcasting tools and content recommendation finding services for audience users. After a certain scale of traffic has been formed by the We Media and audience users, the platform will provide advertising services to advertisers for profit, and advertisers buy advertising services through advertising agencies or directly from the We Media platform. For example, Tik Tok offers different forms of launch screen ads (static or dynamic ad displays when users log in to the software) and information flow ad services (targeted based on users' interests).
We Media platforms differ significantly from traditional media platforms in terms of their operating models. Traditional media platforms mainly serve audiences and advertisers, such as magazines and television. Platforms provide free or paid content services to audiences by producing their own content or buying content rights from content providers, and provide advertising services to advertisers for advertising profits. The content of traditional media platforms will be dominated by the platform, with the screening and auditing by the platform or professional institutions before publishing, and the information is more constrained, but with higher professionalism and organization. Compared to traditional media, the communication on We Media platforms is instant, convenient, continuous, diverse and interactive. Platforms have a basic responsibility to monitor content and the quality of the content depends on the We Media. Meanwhile, because of the popularization of content distribution channels, audience users on the platform are not only content consumers, but also convert into content publishers under certain conditions, while We Media content is published, they also get content from other content publishers and become content consumers of the platform.

\section{STUDY ON WE MEDIA PLATFORMS BASED ON THE BILATERAL MARKET THEORY}

\subsection{Bilateral market theory and media platform research}

The bilateral market theory proposed by Rochet and Tirole $^{[2]}$, as an emerging discipline in industrial organization theory, provides important theoretical guidance for the operational decisions of platform-based firms. According to Rochet and Tirole's definition, consider a platform that charges prices and to buyer and seller users interacting (or trading) on the platform, respectively, and when the total level of prices charged by the platform to buyers and sellers is constant, changing the prices of either buyer or seller users affects the total number of transactions $\mathrm{V}$ on the platform; this type of platform is called a bilateral market. A platform where the total traded volume $\mathrm{V}$ is only related to the total price level is a unilateral market.

Evans $^{[3]}$ divides bilateral markets into three categories, Market makers, such as the intermediary industry: real estate agents, marriage agents; Demandcoordinator, such as Windows systems, Android systems and other operating systems; and Audience makers, such as the media industry such as newspapers, magazines and the television industry. Bilateral markets are characterised by non-neutral price structures, crossnetwork externalities, and multiple user attribution, and 
are an important reference for the operation of platformbased companies.

Most current research on media platforms based on bilateral market theory has focused on traditional media such as television and newspapers, and has concentrated on the analysis of the impact of the choice behavior of both types of users, audience users and advertisers, on the operational strategies of the platforms. These kinds of literature mainly consider cases where platforms produce their own content or buy rights from content providers, focusing on the impact of negative cross-network externalities that advertisers bring to audiences, without considering the impact of the number of content providers. $\mathrm{Yu}$ and $\mathrm{Zhangi}^{[4]}$ argue that the nature of traditional media platforms is closer to a dual unilateral market, with platforms selling content and information to audience users and advertising space and time to advertisers, while there is a lack of endogenous relationship between advertisers and audiences.

In the study of We Media, Zhang and Ling ${ }^{[5]}$ analysed the competitive strategies of content quality decisions and advertising pricing of We Media under the "production and broadcasting + advertising sharing" model based on bilateral market theory. Zhao and Yuan ${ }^{[6]}$ studied the competitive strategies of two We Media that rely on monopolistic media platforms under which registration fees are charged to advertisers and consumers. Both articles see each We Media as a separate bilateral marketplace, connecting advertisers and consumers. As content providers, We Media depend on the distribution channels provided by monopolistic media platforms to distribute their content and share advertising revenue with the platforms.

In the case of the We Media platforms studied in this paper, the We Media, as content providers, are seen as users on one side of the platform. The platform brings together We Media with a need to publish content and consumers with a need to acquire content, and serves advertisements to advertisers for profit. The content is served to audience users by the We Media on the platform. Therefore, the size of the We Media affects the abundance of content available to the audience on the platform, as well as the platform's advertising pricing strategy and profits. We Media, audiences and advertisers form a trilateral market around the platform.

\subsection{Bilateral market characteristics of the We Media platform}

By offering different products or services, We Media platforms bring together three types of audience, We Media and advertisers on the platform, creating a marketplace for the platform, which is an audiencemaking platform. These three types of participants have different interaction activities, for example, We Media have a demand for information delivery to the platform, while the audience has a demand for information access to the platform, and there are complementary needs between these two types of users. For advertisers, the audience on the platform is a potential target for the advertised product or service and the size of their numbers will affect the effectiveness of the advertiser joining the platform. The audience's demand for the platform comes primarily from the content offerings provided by We Media, while the impact of advertising on the audience depends on the advertising preferences of the advertising audience. For example, for advertisingaverse audiences, an increase in platform advertising can reduce the effectiveness of the audience joining the platform. And for advertisements that match the interests of the audience, the increase in advertising increases the effectiveness of the audience. Due to the existence of complementary demands, We Media platforms will encounter the problem of " chicken and egg " in the early stage of development, i.e. when considering whether to join the platform, the audience needs the platform to have a certain size of We Media, to obtain enough rich content, otherwise, they will not join the platform. And when We Media are considering joining a platform, they also need the platform to have a large enough audience or they won't join it.

We Media platforms are known to have a non-neutral price structure: that is, in a bilateral market, changes in the price charged by the platform to users on one side of the table affect changes in the trading volume on the platform and, ultimately, the platform's profits, provided that the total price level remains constant. In a We Media platform, to get users on all sides to demand the platform's services and join at the same time, the platform needs to rationalize its pricing structure according to the elasticity of demand of the audience, the We Media and advertisers, as well as the influence of parameters such as network externalities, in order to achieve the ideal user size of the platform.

Cross-network externalities are typical of bilateral markets, where changes in the number of users on one side of a platform affect the utility of users on the other side of the platform. In traditional media platforms, the richness of the platform's content offerings depends on the number of content products purchased or produced by the platform, and is independent of the number of content providers. While in the We Media platforms, the greater the number of We Media the richer the content offerings published on the platform and the higher the effectiveness gained by the audience joining the platform. Similarly, the larger the audience on the platform, the more clicks and attention the We Media content gets on the platform, and the more revenue advertisers get from posting advertisements on the platform. Hence, platforms need to increase the strength of the positive cross-network externalities that selfpublishing brings to the audience and reduce the negative 
network externalities that advertising brings to the audience, to attract more users to join the platform.

Users on each side of the We Media platform have different attributions. For example, because video or text content has characteristics such as easy reproduction, storage and transmission, the transfer cost of We Media content on different platforms is low, and most of the current We Media platforms adopt the strategy of free content distribution for We Media, therefore, many We Media will choose to publish content on different platforms at the same time to get more plays or clicks, this behavior is called multihoming.

In order to attract more We Media to join the platform and improve the competitiveness of the platform's content, the platform will also use exclusive agreements to provide price subsidies or exclusive services to make the We Media only publish content on the platform, thus making them single attribution. Thus, We Media is characterised by partial multihoming. While users on the audience side will sign up for different We Media platforms at the same time, they will only access content within the same platform per unit of time. For example, in the short video platform competition, audience users may download multiple short video software at the same time, although the user's time is limited, so only one software will be accessed at the same time to watch the content, therefore, the audience users show a single attribution per unit of time. Advertisers, on the other hand, choose to advertise on multiple platforms with multihoming in order to extend the reach of their products. Thus, the characteristics of users of We Media platforms are mainly characterised by multiple attributions to the We Media section, single attribution to the audience and multiple attributions to advertisers. Armstrong ${ }^{[7]}$ suggests that when users on one side of a platform are partially multihoming and those on the other side are single attributed, the single attributed side constitutes a competitive bottleneck in platform competition. At this point the multihoming side has to join the platform to trade with the single attributed user, the platform has certain monopoly power over the multihoming side. Therefore, in the competition of We Media platforms, it is still mainly competition for the single attributed audience, but also for the audience's time, that is, the platform that is more attractive to the audience will also have more competitive advantages.

\section{COMPETITIVE STRATEGIES FOR WE MEDIA PLATFORMS}

\subsection{Price strategy}

In order to break the problem of " chicken and egg " at the early stage of platform development, the operators of We Media platforms can adopt a price subsidy strategy for users on the platform, driving users on both sides of the platform to quickly reach a critical mass of users that can form a positive feedback mechanism ${ }^{[8]}$, to give play to the platform scale effect and ensure the stable growth of the user scale. For example, at the beginning of the Tik Tok platform, a number of influential We Media signed paid video publishing cooperation agreements, and also launched content publishing rewards to attract more We Media to join the platform, so that the platform quickly accumulated a certain scale of We Media and video content at the beginning, and then attracted audiences to join the platform through multi-channel advertising, driving more We Media to join the platform and achieving a significant increase in the size of users in a short period of time. The platform has achieved a significant increase in the scale of users within a short time.

The optimal pricing of the platform for users on each side needs to simultaneously consider and balance the needs of users on each side, and maximize the scale of the platform's users through a reasonable distribution of price levels. We Media platforms should design a reasonable pricing strategy based on the different price flexibility and needs of their audiences, We Media and advertisers. For example, Tik Tok short video platform provides basic services such as content acquisition and content publishing completely free of charge to audience users and We Media with high price flexibility; for We Media with high attention demand, the platform provides paid targeted push value-added services, that is, through big data analysis, video content is targeted and pushed to a specified type of audience to improve video plays and dissemination efficiency; in the audio We Media platform Himalaya FM uses both free and paid models for listener users based on the quality of audio content, while providing audience shares and subsidies to audio publishers to prompt more publishers to join the platform.

\subsection{Content strategy}

\subsubsection{Content positioning strategy}

A differentiation strategy is an important tool for platform competition. At present, there are various We Media platforms on the market, and the competition is becoming intense. To get more users and stand out from the competition, We Media platforms need a clear content positioning strategy so as to gather users with specified preferences and avoid homogenous competition. For example, among the short video platforms, the target audience of the Tik Tok platform is mainly fashionable young people, and the platform is positioned mainly for quality music and videos, offering more rewards and opportunities to showcase We Media who provide quality content. The clear positioning and 
quality content service made the platform stand out in the fierce competition of short video platforms, attracting a large number of users to join the platform in the early stage of its development.

\subsubsection{Content production model}

The content production model of We Media platforms is mainly based on UGC (User Generated Content), i.e. the content of the platform is generated by users. In this model, anyone is free to publish their own content or information through the platform, and the platform's audience can be transformed into publishers of the platform's content, bringing massive amounts of content and user traffic to the platform. However, the downside of the UGC model is that the quality of content varies and the value density is low, which cannot guarantee the long-term stickiness of users. The main content production model of traditional media platforms is PGC (Professional Generated Content), that is, the content of the platform is produced by people or teams with professional information processing and processing capabilities

Content in the PGC model is more professional and insightful, but the content is more expensive to produce and focuses on quality rather than quantity. The UGC model gives users full freedom to express their own opinions thus generating huge traffic. Therefore, how to effectively integrate UGC and PGC models, to bring into play the scale effect brought by the UGC model, and the content advantages brought by the PGC model is the development trend of We Media platforms. There are three main models currently:

- $\quad$ UGC + PGC model. The combination of both $\mathrm{UGC}+$ PGC models makes the content on the platform more diverse, satisfying both the personalisation of user content and the audience's demand for high-quality content. For example, the content providers of Headline, in addition to general We Media, also cooperate with CCTV.com, The Beijing News and other wellknown traditional media. Traditional media, with the help of Headline's extensive user base and information pushing technology based on big data analysis, can realize the accurate distribution and dissemination of the provided content, while the platform, with the help of quality content produced by traditional media, enhances the authority and professionalism of the platform, preserves the freedom of user content sharing and timing, making the platform's content more diversified. This model also promotes the deep integration and joint development of traditional media and new media platforms.

- PUGC model(Professional User Generated Content), that is, professional users produce content. The PUGC model is based on user- produced content, but the producers are more professional, usually content producers with professional experience or a certain reputation in the relevant field. This model preserves the freedom and initiative of the platform's users to produce content, and also enhances the professionalism of the content and the branding of the platform. For example, by inviting users with radio work experience or broadcasting expertise or celebrities in related fields to join the platform, Himalaya FM has enhanced the branding of the platform by virtue of the highquality content posted by such users, thus attracting a large number of listener users to join. In addition, the platform provides training to certified anchors (content producers) on broadcasting skills, content production and communication strategies through the creation of the " Himalayan University" to build them into professional content producers.

- Professionalization of user-produced content. This model is represented by the information We Media platform, Pear Video, where the platform regulates the filming of videos, and the filmmakers (content providers) are responsible for filming and submitting video footage under the requirements, and the professional editors in the platform select the information most needed by the audience from a wide range of video footage, review and professionally edit it, and then present it to the audience, thus forming a standardized and professional content production process. This model of user-produced content and professional processing by the platform simplifies the technical requirements for content production and lowers the professional threshold. This enables audiences to access real and useful information more efficiently in the first instance.

\subsection{Service strategy}

Because of the different interactivity of users on the three sides of the We Media platform, the platform needs to take into account the needs of users on each side and provide quality supporting services, so as to optimise the user experience and increase the stickiness of the platform users. Service differentiation strategy is an important means of platform competition. The basic service of We Media platform is to provide content publishing service for We Media and content access service for audience, and to provide better and richer value-added services for different users' individual needs, to stand out in the increasingly fierce platform competition and form the core advantage of the platform.

For example, in the face of the massive content resources of the We Media platform, in order to enable users to quickly access rich and interesting content, the Headline platform, based on big data analysis technology, establishes a tagging and classification system for the interests and preferences of viewers and 
the content of articles on the platform, thus providing targeted placement services for We Media and personalised content recommendation services for the audience, which not only improves the reading volume (or revenue) of We Media, but also brings better reading results to the audience. At the same time, the platform's advertising is also based on viewers' interests, reducing the dislike that advertising brings to viewers and also increasing the matching rate between advertising products and potential users, greatly improving the effectiveness of advertising.

In response to the advertising needs of advertisers and the traffic cashing needs of We Media, the Tik Tok short video platform relies on the platform's massive We Media and viewer user resources to provide advertisers and We Media with a service platform for advertising content trading and management - the "Xingtu Platform ". Advertisers can publish their own advertising tasks on the platform and select suitable We Media for the production of advertising content. Through the platform, they can control the planning of advertising content, the auditing of filming and video release as well as the data analysis of the advertising effect. We Media users can also take up advertising assignments on the "Xingtu Platform", using video ideas and fan attention to cash in on the traffic. The standardisation of the advertising content trading process and the efficient process control services not only increase the dependence of advertisers and We Media on the platform, but also better utilize the commercial value of the platform.

\section{CONCLUSION}

We have now entered an era where the mobile internet is the medium of communication and there are multiple communication actors. As the traditional communication pattern changes, the ability of individuals to communicate outside the traditional social structure with the help of wireless networks and smartphones has developed like never before, thus greatly liberating the productivity of people's thoughts, ideas or content. The decline of traditional media and the rise of We Media are the result of people's choice of tools for expressing and communicating their ideas. As an important form of economic organization in the digital economy, the openness and innovation of platforms have led to the evolution of products and services. We Media platforms need to further optimize their pricing strategies according to the needs of their users, clearly differentiate their content positioning, reasonably select and design their content production models, and improve their service levels so as to bring into play the network externality effect among platform users, form a positive feedback mechanism, and improve user stickiness to form an advantage in platform competition

\section{ACKNOWLEDGMENT}

This research was supported by the social science and humanity on Young Fund of the ministry of Education (NO. 17YJC630193).

\section{REFERENCES}

[1] Bowman S, Willis C. We Media: How Audiences are Shaping the Future of News and Information[M]. The Media Center at the American Press Institute, 2003.

[2] Rochet J, Tirole J. Platform Competition in Twoside Markets[J]. Journal of the European Economic Association, 2003, 1(04):990-1029.

[3] Evans D S. Some Empirical Aspects of Multi-sided Paltform Industries[J]. Review of network economics, 2003,2(3):191-209.

[4] Yu X Y, Zhang J H. Digital transformation of traditional media and platform development of New Media - an economic analysis based on bilateral market theory [J]. Press Circles, 2012 (5).

[5] Zhang J, Ling C. A new model of media industry-an economic analysis of "We Media"[J]. Review of Industrial Economics, 2015(5).

[6] Zhao Y J, Yuan X J. Research on the revenue distribution and competition strategy of We Media from the perspective of bilateral market theory-Based on Hotelling's competitive pricing model[J]. China's Prices, 2017(12).

[7] Armstrong M. Competition in Two-side markets[J]. The RAND Journal of Economics, 2006, 37(03):668-691.

[8] Evans D S, Schmalensee R. Failure to Launch: Critical Mass in Platform Businesses[J]. Review of Network Economics, 2010,9(04):1-26. 